\title{
A Pellucid approach for PBL using Advanced Mind Mapping
}

\author{
Govil Alok ${ }^{1}$, Vidushi Govil ${ }^{2}$, K Srikar ${ }^{3}$, V Srujana Reddy ${ }^{4}$, M Lohith $^{5}$ \\ ${ }^{1,3,4,5}$ Center for Design, SR University, Warangal, Telangana, India \\ ${ }^{2}$ Blue Blocks Complete School, Hyderabad, Telangana, India \\ ${ }^{1}$ govilalok@sru.edu.in \\ 2vidushi.gth@gmail.com \\ ${ }^{3}$ srikarcherry234@gmail.com \\ ${ }^{4}$ veesamsrujanareddy1999@gmail.com \\ ${ }^{5}$ lohithmarkala0666@gmail.com
}

\begin{abstract}
Engineering education has been revamping its curriculum and teaching methods lately to accompany innovation engineering to aid the fourth industrial revolution. In order to bring efficacious outputs among engineering students and setting up benchmarks in a technological environment to grow as an entrepreneur, a new effective and efficient curriculum infusing design, engineering and technology is sustainably developed. The study explores various dimensions of innovative curriculum and its role in nurturing freshman's perspectives in engineering and its applications are projected using activitybased methods to develop their cognitive psyche. Among many tools, mind mapping has provided a lucid illustration, both in visual and cognitive aspects. These tools were explored in a course introduced in the third year as design thinking and innovation for about 42 students. The primary focus has been to impart design thinking skills thereby making them visionary with a wider perception. The effectiveness of the course was assessed by the surveys and feedbacks and the efficiency from the results obtained by considering pre and post classroom activities. Mind mapping is considered as one of the simplest tools which can be used from primary to master level with ease. The intent of the students and ideations itself prove the efficacy of the tool and its importance in education.
\end{abstract}

Keywords: Mind Mapping, Innovation, Design Thinking, Creativity, Engineering Education, Project based learning

\author{
Govil Alok \\ Center for Design, SR University, Warangal, Telangana, \\ India \\ govilalok@sru.edu.in
}

\section{Introduction}

The fourth Industrial Revolution has had an impact on the curriculum and the methods that are employed to teach at every level of education. The impact of the digital world onto our real world, in the way we live, operate and work has nudged us to rethink the way young adults are educated (Govil Alok et al., 2018). And the impact is the highest on the minds that are training to be future engineers of the constantly changing world. It is imperative now, to find ways to infuse design, engineering and technology, embed it with skills of entrepreneurship, to make it accessible and pervade practical approach solutions (Santhosh Kumar et al., 2018). The human mind with its complex, dense every growing network of synapses, has been a fascinating study for many generations, inspiring tremendous work in the field of Neuroscience (Edwards \& Cooper, 2010). It's evident that the brain does not make linear connections, neither there is a systematic pattern in the way the information is stored (Zampetakis et al., 2007). Rather, it's a non-linear way of establishing associations, often around a concept, forming a structural cohesion of information that can be synthesized together (Mandal, 2014). This amazing, intriguing human technique has inspired us to change the tools that can add meaning, power and speed to the way we can learn. Hence the concept of Mind Mapping is absorbed so readily for the way it simplifies the need of the current generation to assimilate information and arrive at creative solutions (Tee et al., 2014).

\section{Project Based Learning}

Project based learning is a teaching methodology which is entirely student-centred. This pedagogy primarily focuses on delivering knowledge by the exploration of real-world problems and optimizing time using active learning and collaborative methodologies (G. Alok et al., 2018). In project based learning educators play a vital role in involving students to collaborate and work with their peers resulting, a meaningful output. Many innovative ways are drafted by educators in order to imbibe skills such has creativity collaboration, critical analysis, adaptability, Time management (Dym et al., 2005) to combat oncoming challenges. Project based learning pedagogy provides many advantages over traditional pedagogies as follows:

- It is flexible to work either independently or collaboratively with peers in the same working environment.

- It enables students to work from different places yet, envisages collaborative inputs using various tools.

- It promotes professional skills effectively which are highly useful in an individual's life and boost their oncoming careers. 
It promotes blended in-class and distance learning using various active learning methodologies, which provides a better, efficient and effective scope of learning during difficult times such as an outbreak of diseases, pandemic, a disaster where conventional Inclass teachings are paused.

- The primary and crucial attainment of PBL is, it enables students to explore real-world problem scenarios, thereby understanding the needs and challenges which are creatively addressed using innovative skills. These improve their cognitive abilities and tenacity to work.

Many courses use project based learning pedagogies in their curriculum to develop all-round development of students. Usually, a curriculum development process involving PBL pedagogy is composed of three major components, Research, Design and Testing. At SR University many courses such as Product Design Studio, Foundations to Product Design, Engineering Design Process and Design Thinking \& Innovation (Govil Alok \& Saipriya, 2020) have been developed, which are purely activity-based and project based learning courses. It is important to understand that project based learning requires various innovative and collaborative tools for teaching and learning to bring enhanced outcomes (Govil Alok et al., 2020). Out of many tools, mind mapping is one of the fascinating tools that provide multiple benefits for learning this mind mapping tool has been effectively used for brainstorming, pain storming, exploration, diagramming in an open elective course offered in the third year as design thinking \& innovation.

\section{A. Course Overview}

Design Thinking \& Innovation is an open elective course introduced at III Year where student's metacognitive abilities are promoted (Astriani et al., 2020) using design methodology following a user-centric approach. In Table 1. basic information of the course is provided and an overview of the course taught, could be highlighted as follows:

- What is the Meaning of design thinking - Design thinkers personality profile - The overall process of design thinking - Inspiration, Ideation and Implementation - Steps in design thinking.

- Understanding the Context - Conducting user research - Identifying insights - Establishing design requirements - Journey mapping, Mind mapping and Value chain analysis - Emergence of a new concept Concept generation and development - Creating idea pitches.

- Tools for Design Thinking An instrument real time Design interaction capture and Analysis - Tele-Board - Enabling efficient collaboration in Digital Design.

- $\quad$ Testing Hypothesis and Prototyping by Creating and testing hypotheses /assumptions - Avoiding confirmation bias and groupthink - Experimentation - Rapid prototyping - Storytelling
- Building Customer Relations Customer co-creation, Building blocks of interaction - Dialogue, Access, Risk - Benefits, and Transparency, Interaction between firms and consumers. Implications.

Table 1. Basic Information

\begin{tabular}{|c|c|}
\hline Branch & All Branches (Open Elective) \\
\hline Course & Design Thinking \& Innovation \\
\hline Prerequisite & $\begin{array}{c}\text { Product Design Studio, Engineering } \\
\text { Design Process }\end{array}$ \\
\hline Year / Semester & III/II \\
\hline No. of Students & 60 \\
\hline No. of Faculty & 1 for 30 \\
\hline CIE & 50 \\
\hline SEE & 50 \\
\hline Credits & 3 \\
\hline Hours & $2+1$ \\
\hline
\end{tabular}

B. Course Objectives and Outcomes

Objectives and outcomes of the Design Thinking \& Innovation course are as follows:

Course Objectives:

Students will be able to

1. Define the need for creative and design thinking.

2. Recognize various discovery phases and insights in idea generation.

3. Prepare the Idea generation concept.

4. Experiment group project work by using various techniques.

5. Evaluate the delivery phase and prototyping.

Course Outcomes:

At the end of the course, the students will develop an ability to

1. Recall various creative and design thinking models.

2. Convert ideas into future products/services.

3. Discover new ideas through team workshops.

4. Compare the difference between concept visualization and prototyping.

5. Produce prototypes based on design thinking.

6. Setup new stranded in converting raw ideas into reality.

7. Define how to build customer relations.

8. Summarize the importance and need for creative and design thinking.

\section{Design Thinking Process}


The Design Thinking process is a universally accepted model to nurture Creativity, especially in project-based learning. This process is a non-linear and iterative process that provides educatee to understand and analyze the problems and challenges associated with the users, redefine needs, and conceptualize novel and effective solutions to address the problems. The key highlights of the Design Thinking Process could be put forth as:

- $\quad$ Provides a wider perspective to observe, understand the user's problem by empathizing over their true needs rather than focusing on hearsay needs.

- $\quad$ Derives and defines challenges by profound analysis identifying root causes of the problem by exploring the user's cultural, personal and professional background.

- $\quad$ Boosts creative thinking by promoting ideal and innovative solutions for problems faced by users in their personal and professional environments. It highly appreciates out of the box thinking in exercising Creativity for the development of concepts.

- Provides an array of models and prototypes developed as a result of conceptualization and derived from user feedback and suggestions.

- Eliminates errors and aligns with the deliverables thereby Optimising and improving product utility and efficacy. It provides an iterative process until the standard mark of expected outcomes are reached.

Generally, the Design Thinking Process involves various stages from empathizing with the user's problem, creating solutions to pitching and testing Solutions addressing challenges. These stages can be listed in five categories as

$\begin{array}{ll}\text { - } & \text { Research } \\ \text { - } & \text { Define } \\ \text { - } & \text { Ideate } \\ \text { - } & \text { Prototype } \\ \text { - } & \text { Test }\end{array}$

These stages of the Design Thinking Process were worked out in a Course namely Design Thinking \& Innovation where Mind Mapping was extensively used and results were elucidated using various mind mapping methods. Few examples are illustrated under case studies. During Research an unconditional and uncontrolled mind maps were derived whereas in defining problems more conditional and controlled Mind Mapping was promoted.

\section{Advanced Mind Mapping}

Tony Buzan in 1970 developed a mind mapping technique whose true and many advanced versions are used to date in various studies and specializations. As per Buzan, mind mapping is an expressive tool that represents radiant thinking which a representation of the functioning of the human mind is. It is a Graphical representation solving Complex routing and interpretation thereby unlocking the true potential of one's brain. It brings lucidity in thinking and enables one to understand and learn effectively and efficiently. Mind mapping is such an aesthetic tool that provides flexibility to showcase all the information obtained from several sources in simple structural form using vibrant or simple colors with keywords. Few of the essential characteristics of the Mind Map are as follows:

- the domain focussed is put at the center are there in lettering, sign, symbol or image

- $\quad$ offshoots from the domain (subdomain) emerge out from Central domain as branches.

- these branches either have keywords or images represented at the end node or upon the line.

- $\quad$ these branches are further emphasized forming in nodal networks connected further expressing diverse information highlights.

Mind mapping is such a powerful tool that boosts the creative cognizance in one's brain, predominantly the right brain. It enables the person to radiate logical and creative thoughts in visual patterns. It creates a significant balance between the logical and creative aspect thereby prompting both the right and left brain to think and persuade effectively and uplifting outcomes

\section{Significance}

Mind Mapping is a pictorial representation of ideas, words, or tasks in a nodal network, covering the whole domain by showing characteristics glimpses of it using symbols, keywords, signs and abbreviations. This method promotes and boosts learnings in visual thinking, Creativity and narrows the pathway towards innovative solutions. The beauty of using this method is, it encapsulates the whole content in a single page using various innovative and attractive traits of Mind Mapping.

Mind Mapping has shown a promising result in almost all genres of works from Primary to Graduation. It has increased the creative cognition and productivity of students by a greater margin when compared with traditional approaches. Apart from categorizing and summarizing the content on a single page using various relations and brainstorming methods, it also enables one to align their thoughts and vision for better outcomes. Using variable schemes of colors and visuals, this approach also heightens one's Memory by grasping the key highlights. Mind Mapping has been used extensively in various fields of education and professional background for information or representation. It is a Creative fun tool for primary learners who put a wide array of information using colorful texts and images on a single board. On the other hand graduates and professionals use it to explore the domains and understand the root cause of problems by analyzing various functional aspects. 


\section{Softwares}

With the changing time of the modern world, there has been a significant growth towards Digitization. Almost every tool used today has been made digitally available to provide ease and comfort for use and practice. Even labs have been made virtually available, which provides a better understanding of equipment and experiments. Mind Mapping usually takes a good effort and time as it requires cognitive inputs and is considered to be a part to whole process where any error leads to a redo of the whole process. To eliminate such difficulties, advanced mind mapping methods using software applications have been evolving since then. Many software applications are being widely used in various forms involving Mind Mapping techniques around the world. An example using MiMind application for Exploration is shown in Fig. 1 and a circumferential Mind Map using Mindly is illustrated in Fig. 2

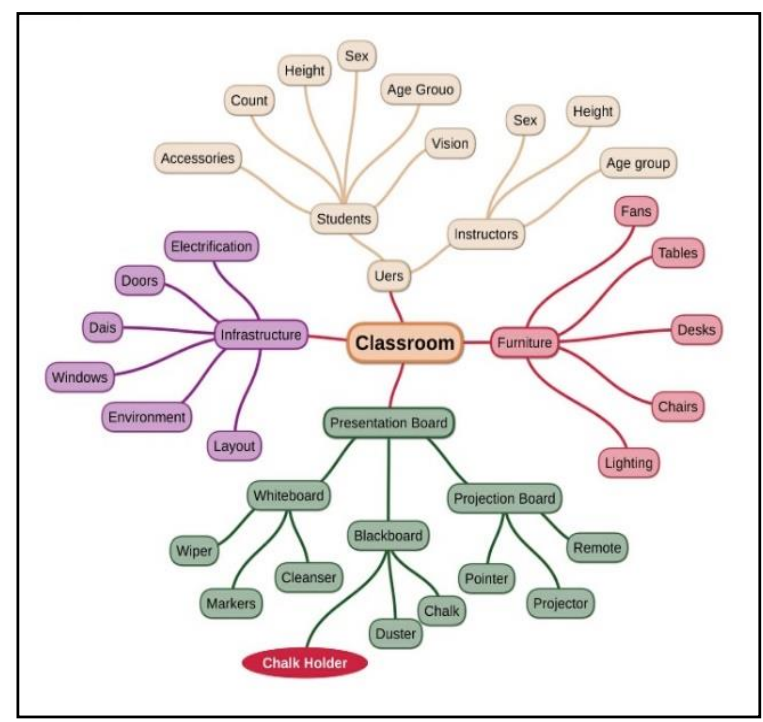

Fig 1. MiMind Application - Exploration using Mind Mapping

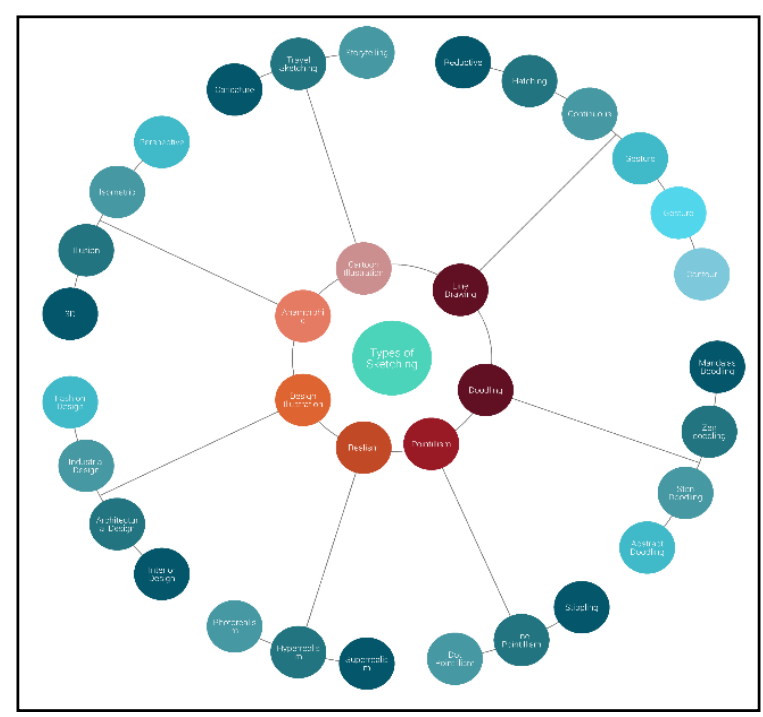

Fig 2. Mindly Application - Circumferential Map
The popularity of Mind Mapping Softwares used varies upon the professionality of the user. Few popular Mind Mapping software applications in use today are as follows:

1) Exclusive Mind Mapping software applications
- Coggle
- MindMeister
- $\quad$ MiMind
- $\quad$ XMind
- Mindly
- Mindomo

2) Collaborative Mind Mapping software applications

- $\quad$ Miro

- Microsoft visio

- Mindomo

- Padlet

- Ayoa

- Lucid chart

3) Software applications for Complex Networking and visualization

- $\quad$ Lucid charts

- Miro

- SmartDraw

Apart from these Software applications providing advanced features, many other Software applications are trending, which provide basic mind mapping features, which can be used by any professional. Even smart boards and graphic tablets are being used to digitally draw mind maps, providing required organic flavor and digital benefits.

\section{Case Studies}

As discussed earlier, there are abundant of features of Mind Mapping techniques which could be put to use in any form. During the Course Design Thinking \& Innovation, Mind Mapping was extensively used by students in many ways to understand, analyze, explore and illustrate their views. Integrating the Mind Mapping tool in Project Based Learning is always challenging if unplanned properly. Though the course is inlined with the Novel Product development and various Tools concerning design thinking were being used, Mind Maps played their part. For Example, during the initial stages of the course, most of the efforts were put into Research and Findings. Collection of Data and Analysing them were a tedious job as the written data records made it difficult for the student to lucidly see the information. Hence during the phase of research Mind Maps which are organic and are unconditional were put to use for exploring their Domains. In Fig. 3 domain with respect to Transportation is explored using Mind Mapping. 


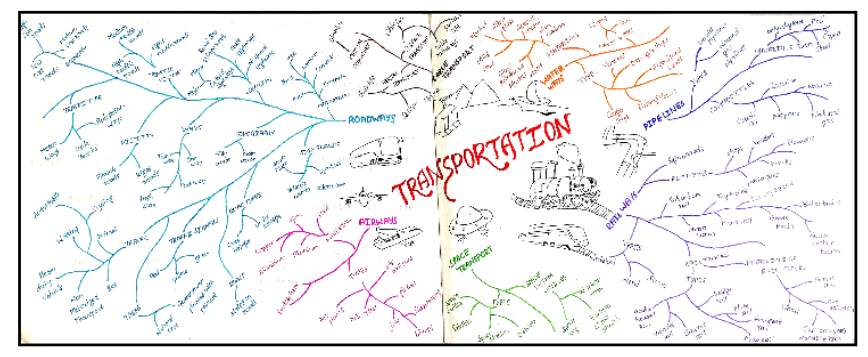

Fig 3. Domain Exploration

Exploring Domains using Mind Map provided greater insights as all the data was put in the single layout where its connectivity and lead were clearly visible. Once the exploration was done, a particular Problem Space for further insights and observations were selected. This was primarily focussed and explored for its various attributes and factors investigating problems ad defining the Needs as shown in Fig. 4

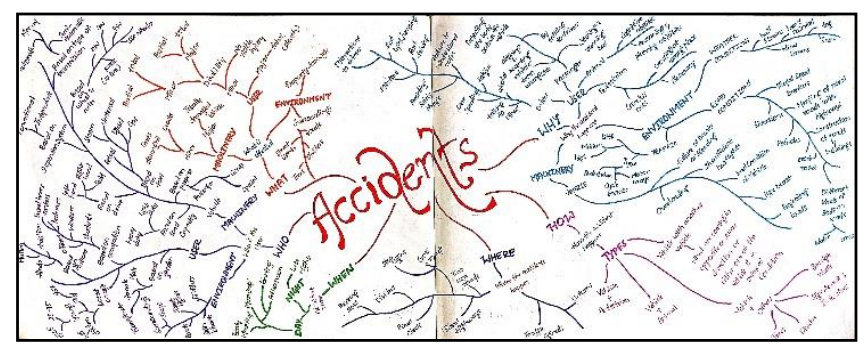

Fig 4. Problem Exploration

Even in ideation, the infographic illustration using mind maps were presented, where multiple Concepts and their functional aspects were shown. A key feature of the concept and its attributes were expressed in keywords and wireframe sketches of concept product were used to showcase as shown in Fig. 5 for various concepts generated for Umbrella.

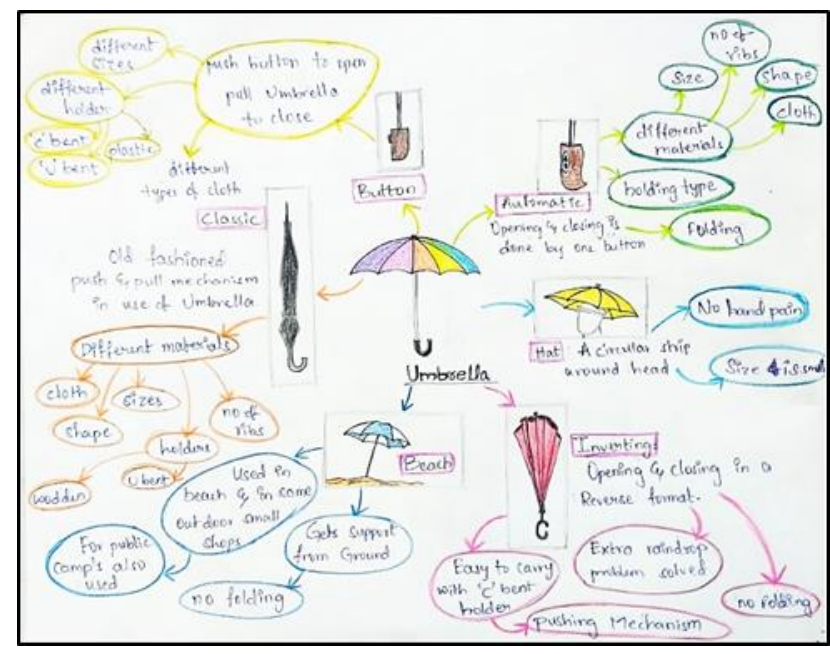

Fig 5. Concepts Developed

Almost in every phase Mind maps were used to pitch in their views with respect to product designing. Even the work plans, Stats, product architecture were showcased using them. Mind Mapping gave flexibility and ease to the students to present their views to their peers, mentors and stakeholders their perception and design, leaving a significant impact and better understanding.

\section{Feedbacks}

Surveys and Feedbacks were taken at the inception of the course and at the end of the Course where student's ideology with respect to PBL Course and their experience was recorded. These Feedbacks were analyzed and converted to statistical inputs giving a brief view of the impact of the course as shown in Fig. 6

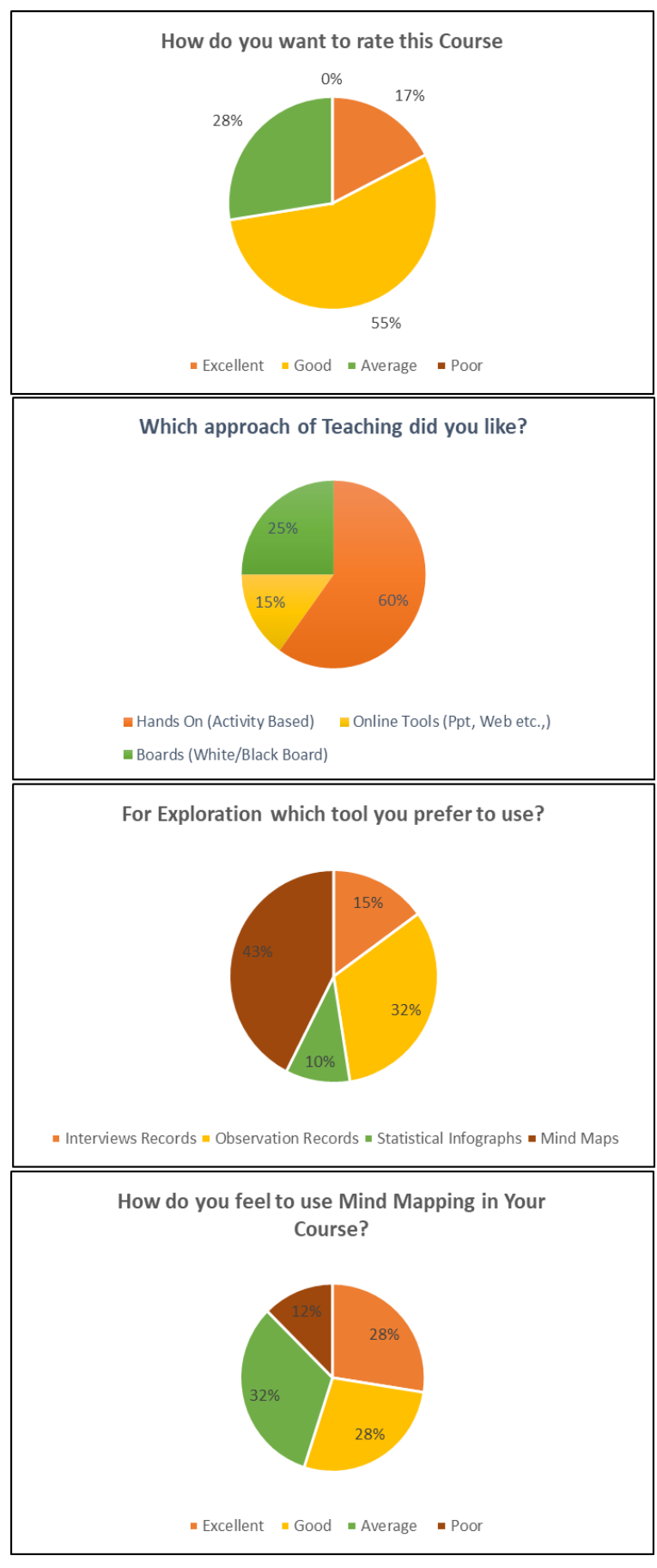

Fig 6. Feedbacks 


\section{Conclusion}

Mind Mapping is one of the important and versatile tools present in both conventional and digital use. It contributes towards promoting creativity, especially in project based learning, by making the young engineering graduates creative thinkers and innovators. The feedbacks pertaining to Mind Mapping tools usage in PBL attorns its importance for its ease of use and flexible representation factors. From Research to Designing a Product and Pitching the tentative inputs attained in the Design Thinking and Innovation Course, Mind Map plays a vital role in lucid representation and facilitates better understanding. As the education technology keeps on evolving, even educators need to imbibe such advanced tools in the curricula to keep up with the changing times. These advanced mind Mapping tools not only save enormous time, but also provides enhanced outputs because of its characteristic features easing the work.

\section{References}

Alok, G., Anushalini, T., \& Condoor, S. (2018). Effective approach towards development of idea through foundations to product design. Journal of Engineering Education Transformations, 31(3).

Alok, Govil, Pothupogu, S., Sampath Reddy, M., Saipriya, P., \& Radhika Devi, V. (2018). Trenchant Pathway to bring Innovation through Foundations to Product Design in Engineering Education. Proceedings of the 6th IEEE International Conference on MOOCS Innovation and Technology In Education, MITE 2018. https://doi.org/10.1109/MITE.2018.8747102

Alok, Govil, \& Saipriya, P. (2020). A corroborative approach for engineering education using design thinking. Journal of Engineering Education Transformations.

Alok, Govil, Saipriya, P., \& Prabhanjan, N. (2020). Persuasive learning strategies for transforming engineering education. Journal of Engineering Education Transformations.

Astriani, D., Susilo, H., Suwono, H., Lukiati, B., \& Purnomo, A. R. (2020). Mind mapping in learning models: A tool to improve student metacognitive skills. International Journal of Emerging Technologies in Learning. https://doi.org/10.3991/IJET.V15I06.12657

Dym, C. L., Agogino, A. M., Eris, O., Frey, D. D., \& Leifer, L. J. (2005). Engineering design thinking, teaching, and learning. Journal of Engineering Education. https://doi.org/10.1002/j.2168-9830.2005.tb00832.x

Edwards, S., \& Cooper, N. (2010). Mind mapping as a teaching resource. Clinical Teacher. https://doi.org/10.1111/j.1743-498X.2010.00395.x

Mandal, H. K. (2014). Brainstorming Approach And Mind Mapping In Synergy Creating Activity. Global Journal of Finance and Management.

Santhosh Kumar, K., Alok, G., Sampath Reddy, M., \& Chandra Sekhar Reddy, N. (2018). An integrated
Multidisciplinary skill development strategy for effective execution from virtuality to reality in Engineering Education. Proceedings of the 6th IEEE International Conference on MOOCS Innovation and Technology In Education, MITE 2018. https://doi.org/10.1109/MITE.2018.8747023

Tee, T. K., Azman, M. N. A., Mohamed, S., Mohamad, M. M., Yunos, J., Yee, M. H., \& Othman, W. (2014). Buzan Mind Mapping: An Efficient Technique for. International Journal of Social, Behavioral, Educational, Economic, Business and Industrial Engineering.

Zampetakis, L. A., Tsironis, L., \& Moustakis, V. (2007). Creativity development in engineering education: The case of mind mapping. Journal of Management Development. https://doi.org/10.1108/02621710710740110 